$\begin{array}{ll} & \text { Etnográfica } \\ \text { etnográfica } & \text { Revista do Centro em Rede de Investigação em }\end{array}$

Antropologia

vol. $18(2) \mid 2014$

Vol. $18(2)$

\title{
Memória do Centro de Estudos de Antropologia Cultural
}

Centro de Estudos de Antropologia Cultural: a brief memory

\section{Carlos Ramos Oliveira}

\section{(2) OpenEdition}

Journals

\section{Edição electrónica}

URL: https://journals.openedition.org/etnografica/3682

DOI: 10.4000/etnografica.3682

ISSN: 2182-2891

\section{Editora}

Centro em Rede de Investigação em Antropologia

\section{Edição impressa}

Data de publição: 1 junho 2014

Paginação: 307-310

ISSN: 0873-6561

\section{Refêrencia eletrónica}

Carlos Ramos Oliveira, «Memória do Centro de Estudos de Antropologia Cultural», Etnográfica [Online], vol. 18 (2) | 2014, posto online no dia 09 julho 2014, consultado o 09 fevereiro 2022. URL: http:// journals.openedition.org/etnografica/3682 ; DOI: https://doi.org/10.4000/etnografica.3682

\section{(c) (1) (8)}

Etnográfica is licensed under a Creative Commons Attribution-NonCommercial 4.0 International License. 


\section{Memória do Centro de Estudos de Antropologia Cultural}

\section{Carlos Ramos Oliveira}

No final dos anos 60 o autor decidiu estudar antropologia, tendo travado conhecimento com o Prof. Jorge Dias e a sua equipa do Centro de Estudos de Antropologia Cultural (CEAC). Integrado nessa equipa desde 1970, concluiu e apresentou a sua dissertação de licenciatura em 1971, um estudo de comunidade da Fuzeta, no Algarve. Em 1972, ao longo de vários meses, na zona a ser inundada pela barragem de Cahora Bassa, efetuou um levantamento etnográfico sobre os tauaras do Vale do Zambeze, trabalho que veio a ser publicado em 1976. Em 1973, como bolseiro do British Council, frequentou a London School of Economics, com o objetivo de aprofundar conhecimentos no âmbito da abordagem ecológica de populações humanas. Em 1974, a ausência de perspetivas profissionais levou-o a deixar o CEAC, a cuja equipa, contudo, permaneceu ligado por fortes laços de amizade.

PALAVRAS-CHAVE: CEAC, Jorge Dias, Fuzeta, tauaras, London School of Economics.

Centro de Estudos de Antropologia Cultural: a brief memory - At the end of the sixties, the author decided to study Anthropology, having made acquaintance with Prof. Jorge Dias and his team at the Centro de Estudos de Antropologia Cultural (CEAC). In 1970 he joined this team and, in 1971, he finished and submitted his graduating dissertation, a community study of Fuzeta, a fishing village in the Algarve. In 1972, for several months, he gathered data for an ethnological report on the Tawara of the Zambezi valley, a people that lived in the area to be flooded by the Cabora Bassa dam; this work was later published in 1976. In 1973 he studied at the London School of Economics, seeking to further his knowledge on the ecological approach in the study of human populations. In 1974, in view of the lack of professional perspectives, he quit the CEAC, although he kept lifelong bonds of friendship with the CEAC team.

KEYWORDS: CEAC, Jorge Dias, Fuzeta, Tawara, London School of Economics.

OLIVEIRA, Carlos Ramos (carlosoliveir21@hotmail.com) - Portugal. 
FINAL DOS ANOS 60. NAQUELE TEMPO, ESTAVA EU SEM SABER O QUE fazer com a vida. Regressado do distante Timor, ficara um "doente" da ilha do sândalo. Achava Portugal completamente desinteressante e só me apetecia partir. Para longe, algures nos trópicos, onde outros mundos e outras vivências me chamavam. Vejo então notícia da criação, no ISCSPU (Instituto Superior de Ciências Sociais e Política Ultramarina), do curso de licenciatura em Antropologia, o primeiro em Portugal, e a possibilidade de viajar por esses mundos a partir do conhecimento científico apontou-me decisivamente o caminho. Foi assim, por via de uma motivação, digamos, algo romântica, que cheguei à antropologia.

A figura inspiradora do curso era o professor Jorge Dias, português do mundo e renovador dos estudos de antropologia em Portugal. A sua simplicidade e encanto pessoal cativavam desde o primeiro contacto. As suas aulas, sempre cheias, diziam de um mestre autêntico. Era também diretor do Centro de Estudos de Antropologia Cultural (CEAC) e do Centro de Estudos de Etnologia Peninsular (CEEP), onde tinha a colaboração de companheiros e amigos de uma vida: Margot Dias, sua mulher, Fernando Galhano, Ernesto Veiga de Oliveira, Benjamim Pereira e António Carreira.

Devo ao professor João Pereira Neto a oportunidade de conhecer de perto essa equipa, com quem a empatia foi imediata, o que permitiu que, antes mesmo de concluir o curso, estivesse já a trabalhar no CEAC, no Palácio Vale Flor.

$\mathrm{Na}$ altura, Jorge Dias e Margot Dias centravam-se, ainda, na conclusão da obra monumental sobre os macondes de Moçambique (Dias 1964; Dias e Dias 1964, 1970). Fernando Galhano, a par da elaboração e participação em estudos de cultura material, tinha a seu cargo a conservação do acervo do Museu de Etnologia, anexo ao CEAC, ainda não aberto ao público. Ernesto Veiga de Oliveira e Benjamim Pereira continuavam o seu incessante e ciclópico trabalho de pesquisa no âmbito da etnografia portuguesa. António Carreira, a quem cabia assegurar as tarefas administrativas e burocráticas, prosseguia em paralelo trabalhos de investigação sobre questões de natureza etnográfica e histórica, com especial incidência em Cabo Verde e na Guiné. Os dias decorriam numa atmosfera brilhante, de entusiasmo pelo trabalho e pelo conhecimento, e de amizade profunda e antiga, celebrada todos os dias nos almoços na famosa tasca das "cadelinhas", do Alto de Santo Amaro, afetuosamente rebatizada de "Ritz" e palco de momentos inesquecíveis na memória da equipa de Jorge Dias.

No que me respeita, quando ingressei no CEAC estava já a efetuar o trabalho de campo para a dissertação de licenciatura, a qual consistia num estudo de comunidade da Fuzeta, no Algarve, trabalho que prossegui até à sua conclusão. Recordo o esforço para enquadrar conceptualmente a realidade empírica com que contactava todos os dias durante o trabalho de campo e para produzir um modelo organizacional coerente com aquela realidade. Recordo, igualmente, 
o principal erro que cometi, com a minha falta de experiência, ao tratar a questão da estratificação social, forçando-me a integrá-la numa visão teórica de classes, quando a diferenciação entre as condições de "marítimo" e "terrestre" tinha muito mais a ver com a realidade - erro que tive oportunidade de corrigir em trabalhos posteriores e, desde logo, no próprio título de uma comunicação apresentada num seminário sobre teoria antropológica realizado no Departamento de Antropologia da London School of Economics, e que utilizei como sumário em inglês da publicação da dissertação - Land and Sea as Categories in the Social Organization of a Portuguese Village. ${ }^{1}$

Decisivo para a minha formação teórica foi, na altura, o encontro com Twig Johnson, antropólogo americano que viera a Portugal realizar trabalho de campo em Cabanas de Tavira, para o seu doutoramento em Columbia. Discípulo de Marvin Harris, deu-me a conhecer a poderosa obra teórica deste antropólogo americano, em particular na área da história do pensamento antropológico e do chamado materialismo cultural, a qual, de forma profunda e definitiva, moldou a minha visão da causalidade sociocultural.

Em 1971, Jorge Dias, que fora incumbido da coordenação da investigação antropológica na área a ser inundada na sequência da construção da barragem de Cahora Bassa, mas a quem faltavam já a saúde e o vigor para ir para o terreno, perguntou-me se estaria disponível para ir até Moçambique realizar o levantamento etnográfico possível. Aceitei de imediato, entusiasmado com a perspetiva de realizar trabalho de campo em África e viver uma experiência que tanto ambicionava. De entre os grupos étnicos que habitavam na zona em causa, optei pelos tauaras, de longe o mais numeroso e com algumas características que me interessavam particularmente, como as diferentes adaptações decorrentes da proximidade ou afastamento do rio Zambeze. A situação de guerra, que então ocorria já na região, dificultou bastante, sem contudo impedir totalmente, a realização da pesquisa de campo, que teve lugar durante duas permanências no terreno, num total de cerca de quatro meses, em 1972. O estudo resultante, uma monografia intitulada Os Tauaras do Vale do Zambeze, ficou concluído em 1973, não sendo a sua publicação considerada oportuna, na altura, pela Junta de Investigações Científicas do Ultramar, razão por que apenas em 1976 veio a ter lugar.

Em 1973 tive ainda a preciosa oportunidade, como bolseiro do British Council, de frequentar a London School of Economics, para realizar pesquisa e aprofundar conhecimentos na área da abordagem ecológica no estudo de populações humanas. Para além de tudo, foi decisivo para perceber o que podia ser o funcionamento e a vida de um departamento de antropologia numa escola de

1 A publicação, prevista para dois números consecutivos da Revista de Estudos Políticos e Sociais do então ISCSPU, foi interrompida após o primeiro daqueles números, na sequência do 25 de Abril. Assim, o texto integral da dissertação apenas foi publicado em separata, com uma tiragem de 50 exemplares. 
referência, o debate vivo e fecundo, a troca de ideias e experiências, a produção académica.

Nesse mesmo ano, subitamente, faleceu Jorge Dias. Regressado da minha permanência em Londres, as perspetivas profissionais apresentavam-se desanimadoras e os problemas com a publicação do trabalho sobre os tauaras também não ajudavam. No início de 1974 deixei o CEAC, mas a lembrança dos luminosos tempos partilhados com a inesquecível equipa de Jorge Dias ficarão comigo enquanto viver.

\section{BIBLIOGRAFIA}

DIAS, Jorge, 1964, Os Macondes de Moçambique, vol. I: Aspectos Históricos e Económicos. Lisboa, Junta de Investigações do Ultramar.

DIAS, Jorge, e Margot DIAS, 1964, Os Macondes de Moçambique, vol. II: Cultura Material. Lisboa, Junta de Investigações do Ultramar.

DIAS, Jorge, e Margot DIAS, 1970, Os Macondes de Moçambique, vol. III: Vida Social e Ritual. Lisboa, Junta de Investigações do Ultramar.

OLIVEIRA, Carlos Ramos de, 1976, Os Tauaras do Vale do Zambeze. Lisboa, Junta de Investigações Científicas do Ultramar. 